\title{
CALIPSO observations of volcanic aerosol in the stratosphere
}

\author{
Larry W. Thomason*a, Michael C. Pitts ${ }^{\mathrm{a}}$ \\ ${ }^{a}$ NASA Langley Research Center, Mail Stop 475, Hampton, VA USA 23681-2199
}

\begin{abstract}
In the stratosphere, the Cloud-Aerosol Lidar and Infrared Pathfinder Satellite Observations (CALIPSO) has observed the presence of aerosol plumes associated with the eruptions several volcanoes including Montserrat (May 2006), Chaiten (May 2008), and Kasatochi (August 2008). While the dense ash plumes from these eruptions dissipate relatively quickly, CALIPSO continued to detect an enhanced aerosol layer from the Montserrat eruption from the initial observations in June 2006 well into 2008. Solar occultation missions were uniquely capable of monitoring stratospheric aerosol. However, since the end of long-lived instruments like the Stratospheric Aerosol and Gas Experiment (SAGE II), there has been no clear space-based successor instrument. A number of active instruments, some employing new techniques, are being evaluated as candidate sources of stratospheric aerosol data. Herein, we examine suitability of the CALIPSO 532-nm aerosol backscatter coefficient measurements.
\end{abstract}

Keywords: CALIPSO, lidar, stratosphere, aerosol

\section{INTRODUCTION}

Aerosol are a key component of stratospheric composition. The aerosol is primarily composed of sulfuric acid and water where the sulfur originates in the troposphere as naturally or man-made $\mathrm{COS}$ and $\mathrm{SO}_{2}$. Stratospheric aerosol is important because it plays an important role in the heterogeneous chemical processes that lead to ozone destruction as well as an episodically important role in the radiative processes that control climate. Over the past 25 years, the dominant source of stratospheric aerosol has been volcanic eruptions including El Chichón (1982), Nevado del Ruiz/Nyramuragira (1985/1986), and Pinatubo (1991). Since 2000, the stratosphere has been at a quasi-steady state where variability is dominated by natural seasonal and quasi-biennial cycles and by several small volcanic events. The most stratospherically significant of these include Ruang (September 2002), Manam (January 2005), and Montserrat (May 2006). Prior to the end of its mission, space-based observations where a primary scientific focus of the Stratospheric Aerosol and Gas Experiment (SAGE II) which operated from October 1984 through August 2005. SAGE II gave a previously unprecedented global view of the formation and decay of stratospheric volcanic aerosol layers. Since the end of its mission and that of the Halogen Occultation Experiment (HALOE), no space-based instrument has routinely produced depictions of stratospheric aerosol though several may be able to do so in the future. These include limb-scatter instruments such as the Scanning Imaging Absorption Spectrometer for Atmospheric Cartography (SCIAMACHY) and occultation instruments like the Atmospheric Chemistry Experiment (ACE). In light of this, we examine the CloudAerosol Lidar and Infrared Pathfinder Satellite Observations' (CALIPSO) Cloud-Aerosol Lidar with Orthogonal Polarization (CALIOP) lidar backscatter coefficient profiles at $532 \mathrm{~nm}$ as a potential source of a scientifically useful stratospheric aerosol product. While we concede that this is challenging, our preliminary study (explained in detail below) suggests that a scientifically viable data product is possible even for the very low aerosol loading period currently observed.

\section{The CALIPSO Instrument and Measurements}

The primary objective of CALIPSO is to provide measurements that will significantly improve our understanding of the effects of aerosols and clouds on the climate system ${ }^{1}$. As part of the Aqua satellite constellation that includes the Aqua, CloudSat, Aura, and PARASOL platforms, CALIPSO is in a $98^{\circ}$-inclination orbit with an altitude of $705 \mathrm{~km}$ that provides daily global maps of the distribution of aerosol and clouds. The CALIPSO payload consists of

*l.w.thomason@,nasa.gov; phone 1757 864-6842; fax 1757 864-2671; http:/www-calipso.larc.nasa.gov/ 
three instruments: the Cloud-Aerosol Lidar with Orthogonal Polarization (CALIOP), an Imaging Infrared Radiometer (IIR), and a moderate spatial resolution Wide Field-of-view Camera (WFC). CALIOP provides profiles of backscatter coefficient at 532 and $1064 \mathrm{~nm}$ as well as the perpendicular polarization component at $532 \mathrm{~nm}$. CALIOP instrument characteristics are shown in Table 1 and the vertical and horizontal resolution of the data products are shown in Table 2. A detailed discussion of CALIOP data products can be found in several references ${ }^{2}$. In the routine processing, the parallel component of the 532-nm backscatter is calibrated to the expected molecular volume backscatter coefficient between 30 and $34 \mathrm{~km}$ altitude where the molecular density is derived from the GEOS-5 atmospheric analyses provided by the Global Modeling and Assimilation Office ${ }^{3}$. The current calibration algorithm does not account for stratospheric aerosol in this altitude range as there are no independent global measurements available. Independent calibrations ${ }^{4}$ occur every $55 \mathrm{~km}$ of the dark side of each orbit and smoothed using a 27-point mean $(1485 \mathrm{~km})$ and interpolated onto the sunlit side. The perpendicular component is transferred from the parallel term using an on-board optical system. The calculation of a stratospheric aerosol product is highly sensitive to the quality of this normalization and any deficiency in the calibration represents a significant obstacle to the successful production of a scientifically useable stratospheric aerosol product.

Table 1. CALIOP instrument characteristics

\begin{tabular}{|rl|}
\hline laser: & $\mathrm{Nd}: \mathrm{YAG}$, diode-pumped, Q-switched, frequency doubled \\
wavelengths: & $532 \mathrm{~nm}, 1064 \mathrm{~nm}$ \\
pulse energy: & $110 \mathrm{~mJ}$ oule/channel \\
repetition rate: & $20.25 \mathrm{~Hz}$ \\
receiver telescope: & $1.0 \mathrm{~m} \mathrm{diameter}$ \\
polarization: & $532 \mathrm{~nm}$ \\
footprint/FOV: & $100 \mathrm{~m} / 130 \mu \mathrm{rad}$ \\
vertical resolution: & $30-60 \mathrm{~m}$ \\
horizontal resolution: & $333 \mathrm{~m}$ \\
linear dynamic range: & $22 \mathrm{bits}$ \\
data rate: & $316 \mathrm{kbps}$ \\
\hline
\end{tabular}

Table 2. CALIOP spatial resolution of down-linked data

\begin{tabular}{|ccc|}
\hline Altitude Range (km) & Horizontal Resolution (km) & Vertical Resolution (m) \\
$30.1-40.0$ & 5.0 & 300 \\
$20.2-30.1$ & 1.67 & 180 \\
$8.2-20.2$ & 1. & 60 \\
$-0.5-8.2$ & 0.33 & 30 \\
$-2.0--0.5$ & 0.33 & 300 \\
\hline
\end{tabular}

\section{CALIPSO OBSERVATIONS OF VOLCANIC AEROSOL}

With its first observations in mid-June 2006, CALIPSO provided detail of condensed material within the stratosphere. These observations included polar stratospheric clouds ${ }^{5}$ and a distinct aerosol plume associated with the 20 May 2006 eruption of Montserrat ${ }^{6,7}$. Over the lifetime of CALIPSO (2006 to the present), the stratospheric impact of several volcanic eruptions have been observed. The most significant of these are listed in Table 3. CALIPSO observations of these eruptions can be visually spectacular. Fig. 1 shows the plume from the Chaiten eruption in May 2008 roughly 2 days after the eruption. The plume, which stretches as high as $16 \mathrm{~km}$, still gives the impression of the billowing irregularity of the violent eruption. This is apparent both in the backscatter coefficient and in the perpendicular term which suggests that the plume is primarily solid ash or ice-coated ash from the eruption. On the other hand, this eruption had only a transient impact on the stratosphere due to the low sulfur content of the volcanic plume and ash has a relatively short lifetime in the stratosphere due to the sedimentation of the relatively large ash particles. 

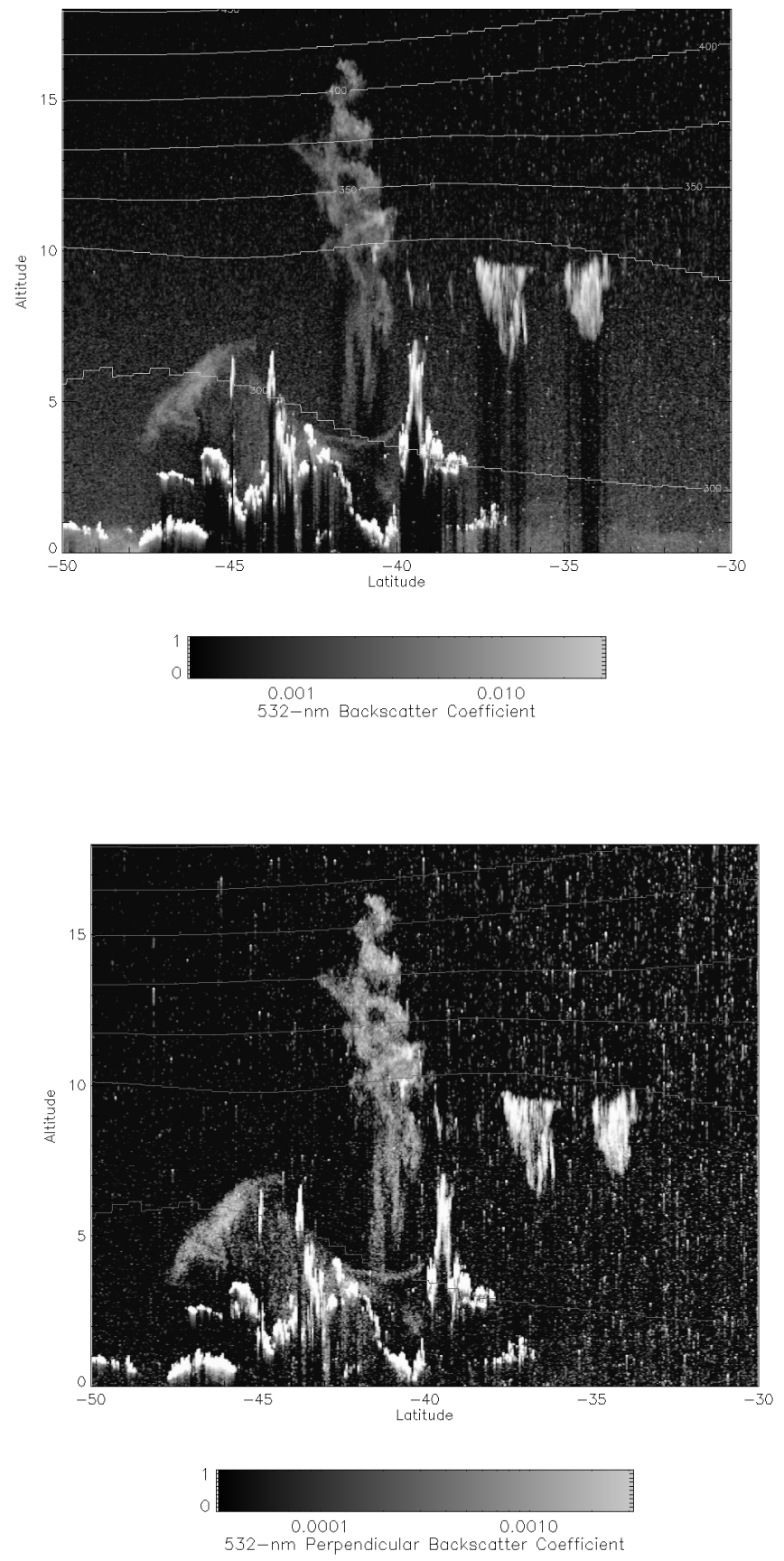

Fig. 1. CALIOP observations on 7 May 2008 of the volcanic plume from the Chaiten (Chile) eruption on 6 May 2008. Upper: 532-nm backscatter coefficient; lower: 532-nm perpendicular backscatter coefficient.

CALIOP makes observations that span from $82^{\circ} \mathrm{S}$ to $82^{\circ} \mathrm{N}$ for 14 orbits per day and, for each profile, backscatter coefficient values at 532 and $1064 \mathrm{~nm}$ is reported up to $\sim 40 \mathrm{~km}$. Since it produces a profile every 1/3 km, CALIOP produces more nighttime profiles in a single day than SAGE II did in its entire lifetime. On the other hand, noise levels in individual profiles are many times higher in the backscatter data than in the SAGE II extinction coefficient profiles. 
Therefore it is not a foregone conclusion that CALIOP backscatter coefficient data is sufficiently robust to be used in stratospheric applications and there are two basic questions that must be answered regarding the use of CALIOP backscatter data for stratospheric aerosol monitoring. One, is there sufficient signal in the backscatter data such that even substantial averaging will produce a viable product? Two, is the calibration sufficiently robust to produce a minimally biased stratospheric product? For instance, we find that daily zonally-averaged nighttime data in 5-degree latitude by $1-\mathrm{km}$ bins (using all available orbits) produces a reasonable depiction that shows the expected features but is still noisy. Using multiple days decreases the noise further and the main features become clearer. For example, a monthly average for August 2006 ( $0.5 \mathrm{~km}$ by 5 degrees) is shown in Fig. 2. No effort to account for the presence of clouds in either the troposphere or within the Antarctic vortex (PSCs) has been made. Nonetheless, a lower tropical stratosphere layer associated with the May 2006 Montserrat eruption and the primary non-volcanic aerosol layer (20 to $25 \mathrm{~km})$ are readily apparent in this image. The CALIOP calibration procedure currently neglects the presence of aerosol above $30 \mathrm{~km}$. As a result, the backscatter data should underestimate the stratospheric aerosol levels particularly in the tropics and is probably responsible for backscatter ratio values less than 1.00 that appear in the lower tropical stratosphere in Fig. 2.

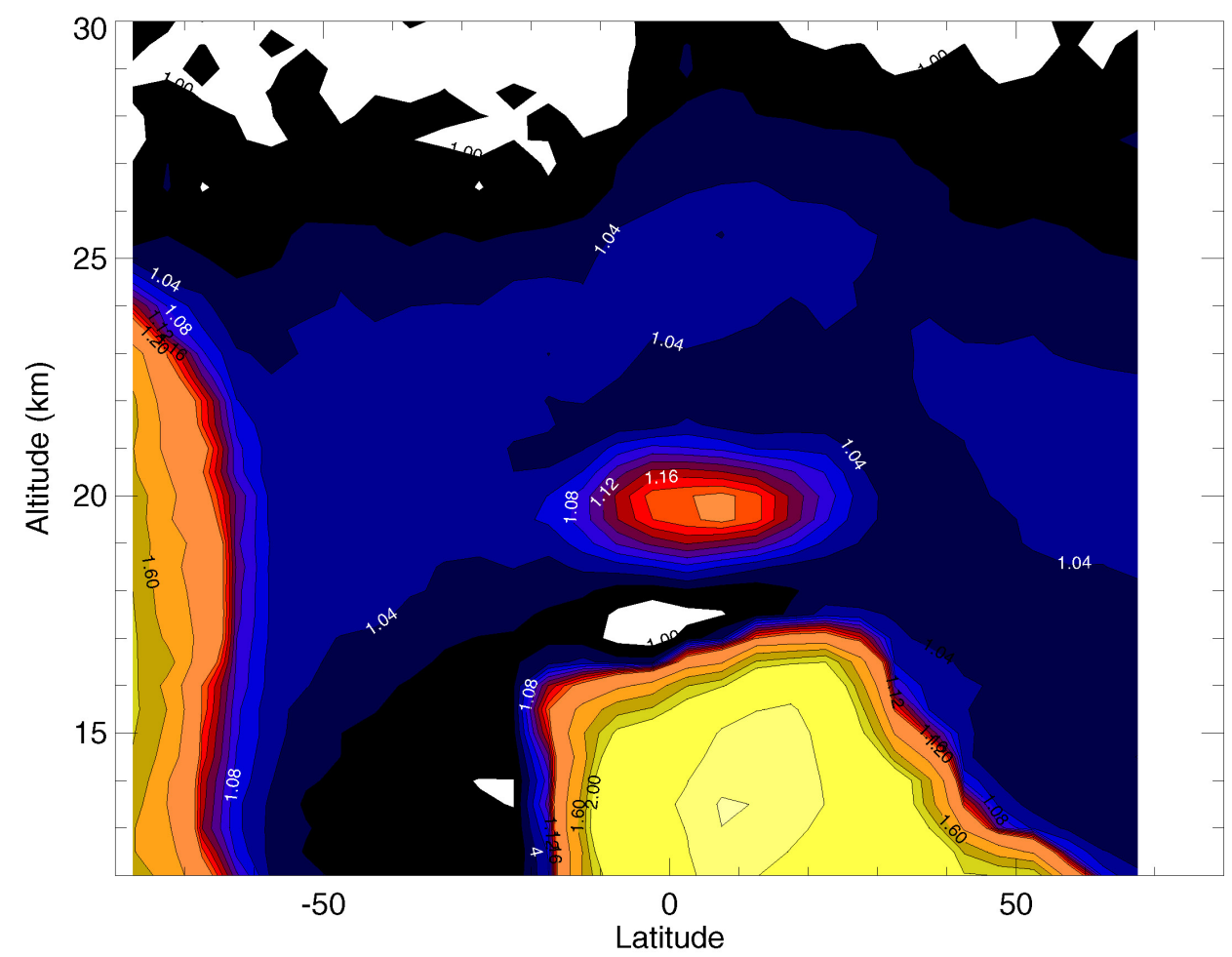

Fig. 2. The averaged 532-nm backscatter coefficient ratio from CALIOP for August 2008. The primary features are in the Antarctic (PSCs), the upper tropical troposphere (clouds), and a small tropical maximum associated with the May 2006 eruption of Montserrat. The weak layer maximum near $24 \mathrm{~km}$ in the tropics and decreasing in altitude toward high altitudes is the main non-volcanic aerosol layer.

Table 3. Notable eruptions with stratospheric effects during the CALIPSO mission

\begin{tabular}{|rl|}
\hline Volcano & Date \\
Montserrat & May 2006 \\
Tavurvur & October 2006 \\
Chaiten & May 2008 \\
Okmok & July 2008 \\
Kasatochi & August 2008 \\
\hline
\end{tabular}




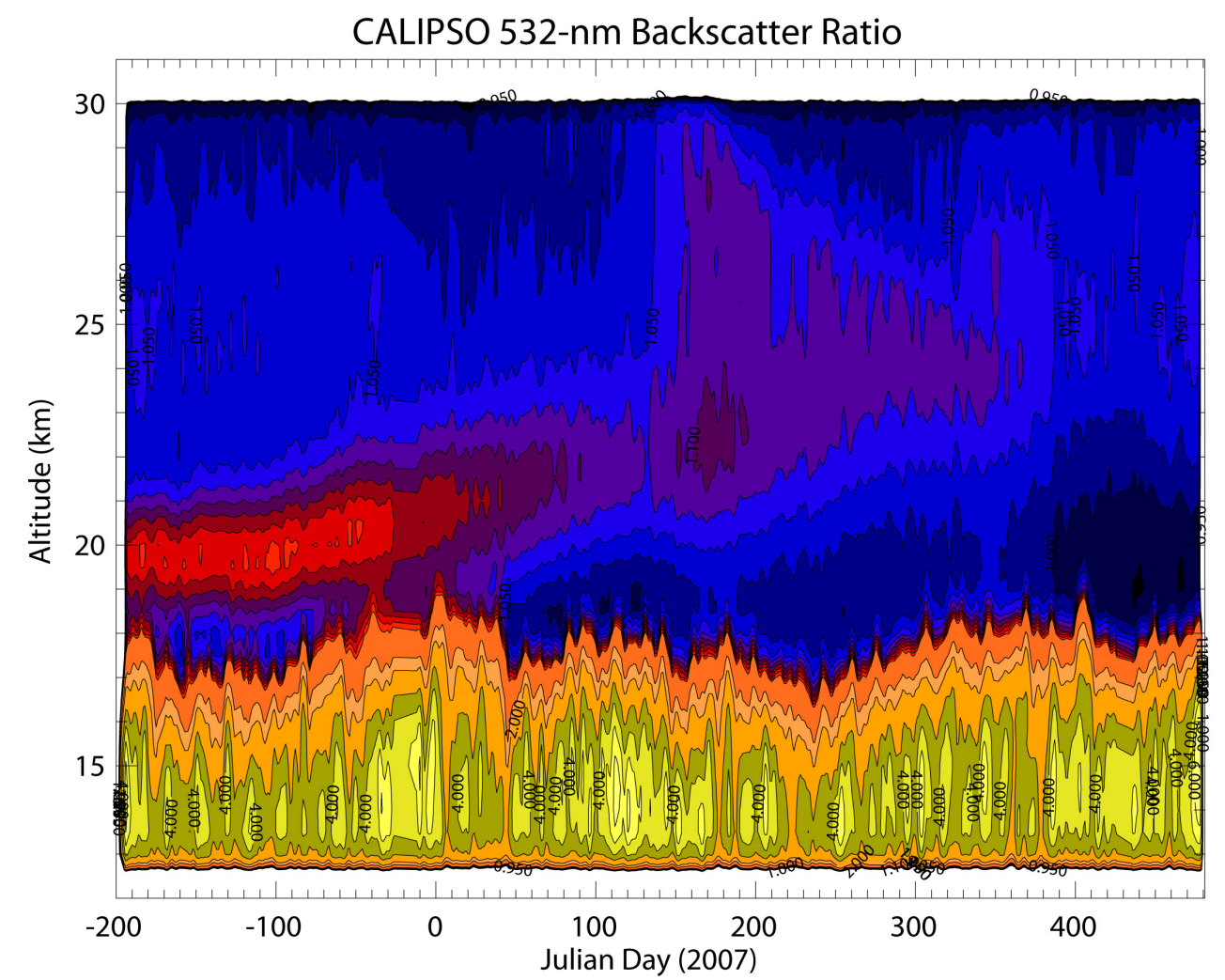

Fig. 3. Daily mean CALIOP 532-nm backscatter coefficient ratio between $5 \mathrm{~S}$ and $5 \mathrm{~N}$ from the start of the CALIPSO mission in June 2006 (about day -200) to the end of May 2008 ( 480). Tropospheric clouds (mostly below $18 \mathrm{~km}$ ) are not cleared. The dense layer centered at $20 \mathrm{~km}$ at the beginning of the record is associated with the Montserrat eruption in May of 2006.

While there may be an absolute magnitude issue, the qualitative backscatter ratio distribution appears promising. The next question is whether its temporal variability is also reasonable. We begin by looking at the temporal behavior of tropical backscatter ratio; this is shown in Fig. 3. The Montserrat aerosol layers lies centered near $20 \mathrm{~km}$ at the beginning of the mission in June 2006 (around day -200) and remains near that altitude throughout 2006. However, beginning in late 2006, the peak of the backscatter ratio layer rises in altitude to $22 \mathrm{~km}$ by mid 2007 and it is near $24 \mathrm{~km}$ by the end of 2007. This behavior closely mimics the pattern observed by SAGE II following a pair of similar small injections of aerosol into the lower tropical stratosphere in 2002 and 2005. This can be seen in Fig. 4 (left) where the initial altitude of the injection for events in September 2002 (Ruang) and January 2005 (Manam) as measured by 1020-nm aerosol extinction ratio are a little lower in altitude (near $18 \mathrm{~km}$ ) than for Montserrat but the aerosol begins its upward rise almost immediately. This difference is controlled by the phase of the quasi-biennial oscillation (QBO) which modulates the general upward transport of air in the tropics. This oscillation can be tracked through the changes in the zonal winds. The phase of QBO is shown in Fig. 5 as a $50 \mathrm{mb}$ QBO wind index from the NCAR/NOAA Reanalysis. Positive phases are noted for strong vertical motions. Both the Ruang and Manam events in the SAGE II record occur near the peak of the positive phase and thus rapid uplift of these layers is not unexpected. On the other hand, Montserrat erupted during the transition from the negative to positive stage which does not reach its peak until later in 2006. As a result, the timing of the uplift of the volcanic layer observed by CALIPSO fits into our understanding of how this process should occur. Another set of interesting features are that the lofted layer in the SAGE II near $25 \mathrm{~km}$ at the end of its record in mid-2005 and a weak layer at $25 \mathrm{~km}$ in the CALIPSO data appears in the early record (2006) that is very similar to the dissipating Montserrat layer in 2008. This layer suggests (speculatively) that CALIPSO may have observed the remnants of the Ruang/Manam layers. Based on past observations, we expect the transport to higher latitudes to occur mainly during the winter. Fig. 6 shows the $42.5 \mathrm{~N} 532-\mathrm{nm}$ backscatter ratio time series. It shows two 
main maxima which begin around the first of 2007 and 2008 at altitudes consistent the main aerosol layer in the tropics. This again argues that the CALIOP stratospheric analysis is capturing real geophysical processes.

It is difficult to assess the bias in the CALIOP data at this time. It is clear that at least in the tropics, the backscatter ratio is too small (since it is occasionally less than 1.0). At the same time, the general lack of a canonical measurement makes a rigorous assessment of bias or the potential for bias difficult. We have made a general effort by converting SAGE II 1020-nm extinction measurements to 532-nm backscatter ratio. An example of this is shown in the right-hand panel of Fig. 4. To do this, we assume that the ratio of 532-nm to $1020-\mathrm{nm}$ extinction coefficient is 3.5 . This is consistent with SAGE II measurements of the $525-\mathrm{nm}$ to $1020-\mathrm{nm}$ extinction coefficient. We also assume a $532-\mathrm{nm}$ extinction-tobackscatter ratio of 10 str. Following this, we convert the extinction ratio (less the molecular ' 1 ') to 532-nm backscatter ratio (less the molecular 1) using a conversion factor of 21 . At best, this conversion process is reliable to $30 \%$ and could be worse at higher altitudes or during non-standard situations like the immediate aftermath of a stratospheric volcanic event. Thus the uncertainty for the unperturbed stratosphere is on the order of \pm 0.01 . The SAGE II values are the most reliable between 18 and $25 \mathrm{~km}$ and given the clear impact of volcanic events the most reliable area in which to compare SAGE II and CALIOP values is in the lower stratospheric minima. For SAGE II the estimated minimum values are about 1.03 whereas the CALIOP minima are between 1.00 and 0.99 after day 100 (to miss effects by Montserrat). This suggests a bias of 3 to $-4 \%$ during this period though the details of CALIOP operation make a consistent single value unlikely. Unfortunately, the 3 to $4 \%$ bias can translate into as much as a $100 \%$ error in the aerosol component of the backscatter ratio. As a result, the quantitative use of CALIOP data for monitoring stratosphere aerosol is not possible at this time.

\section{CONCLUSIONS}

CALIOP provides a compelling qualitative data set in which the impact of several volcanic events can be examined and tracked. This data set clearly shows the upward transport of aerosol in the tropics as well as the seasonal transport to higher latitudes. At the same time, the potential for bias is large particularly for the undisturbed stratosphere and CALIOP is not ready for use as a quantitative data set for stratospheric aerosol monitoring.
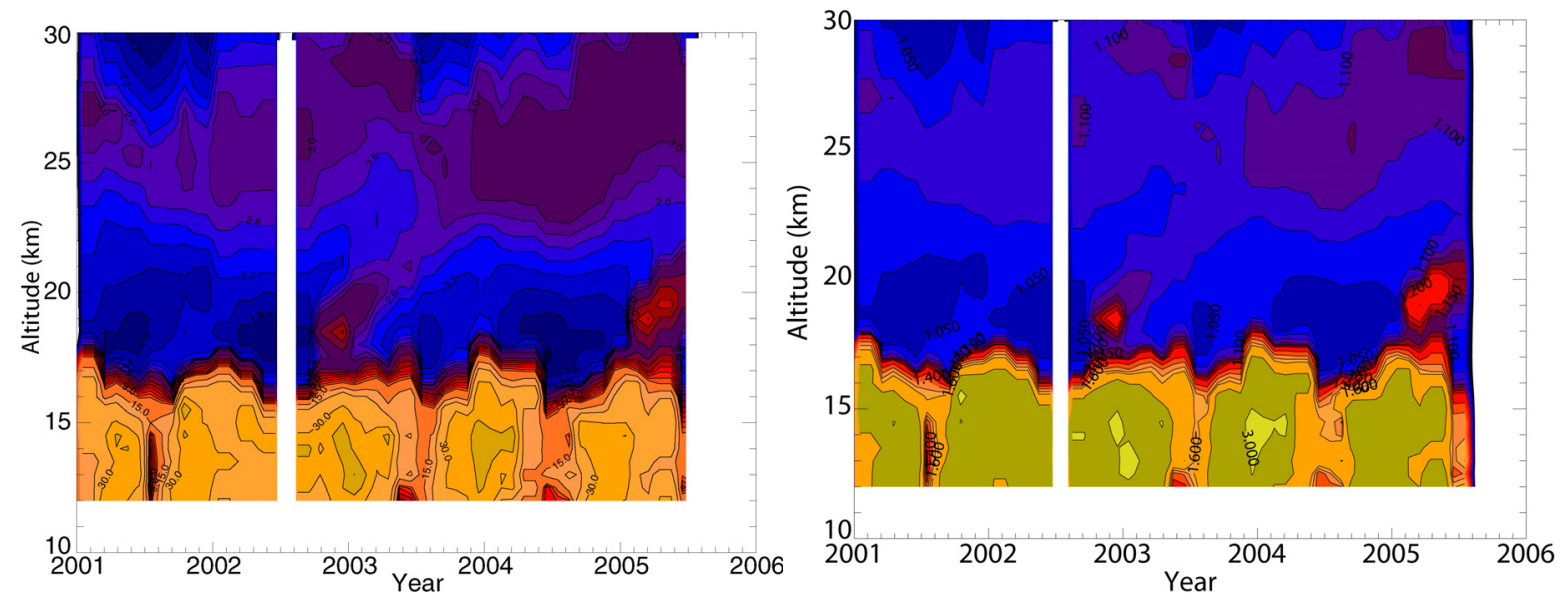

Fig. 4. Right: aerosol extinction ratio (relative to molecular scattering) at 1020-nm as measured by SAGE II and shown as a monthly profiles averaged between $10 \mathrm{~S}$ and $10 \mathrm{~N}$. The effects of two volcanic eruptions are visible in this figure: Ruang in September 2002 and Manam in January 2005. Both show a behavior similar to the Montserrat plume captured by CALIOP in 2006. Left: SAGE II 1020-nm extinction ratio converted to 532-nm backscatter ratio assuming a conversion factor of 21 . 


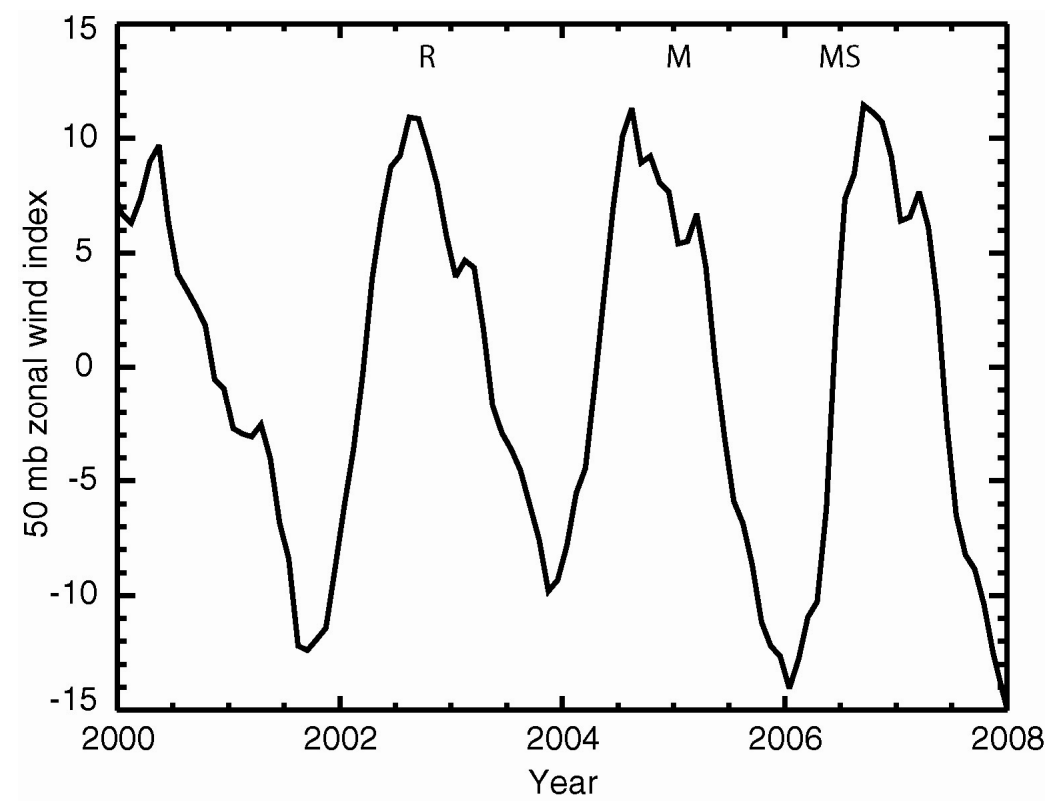

Fig. 5. The QBO $50 \mathrm{mb}$ zonal wind index derived from the NCAR/NOAA reanalysis. The times of three eruptions are denoted by R (Ruang), M (Manam), and MS (Montserrat).

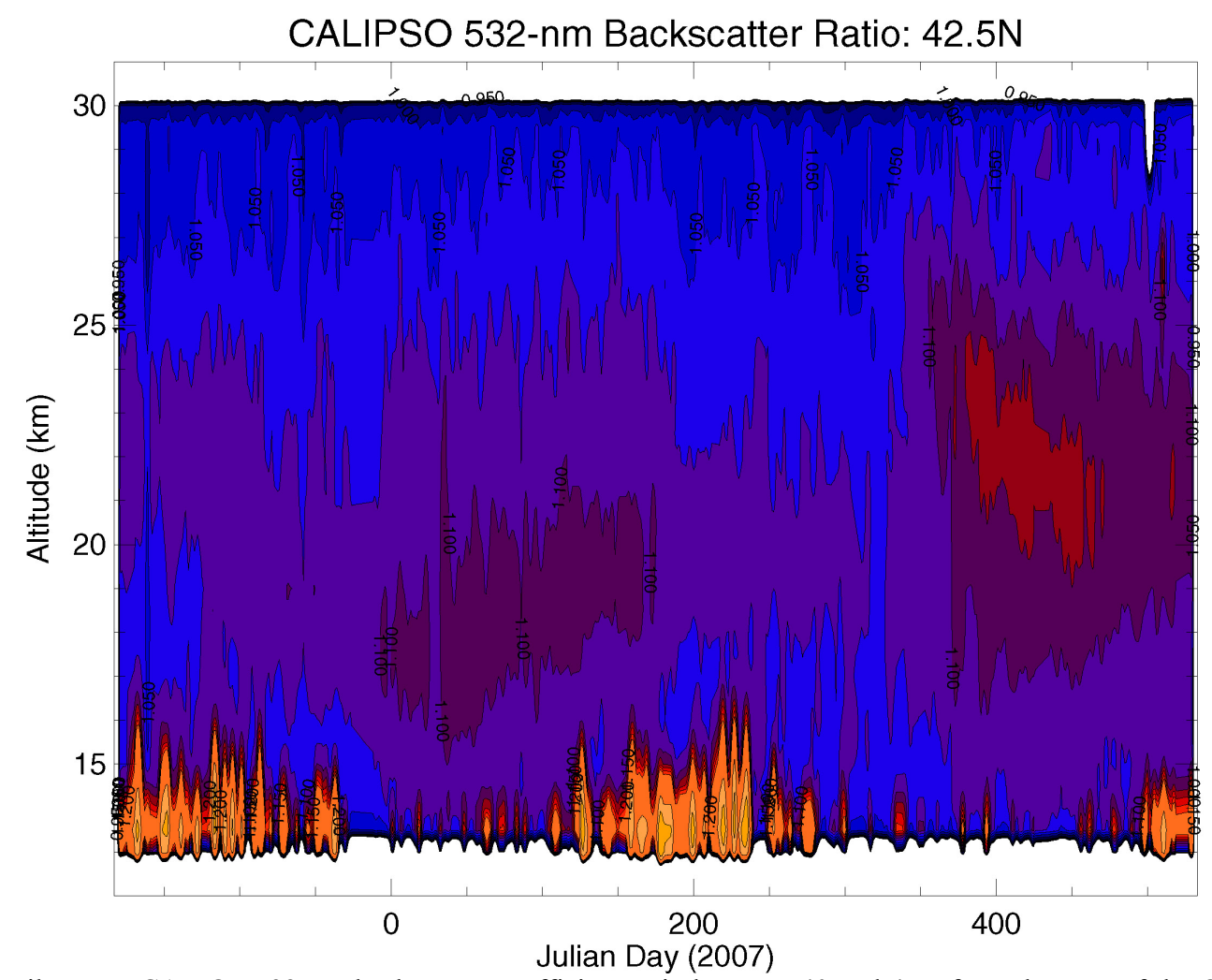

Fig. 6. Daily mean CALIOP 532-nm backscatter coefficient ratio between 40 and $45 \mathrm{~N}$ from the start of the CALIPSO mission in June 2006 (about day -200) to the end of May 2008 ( 480). Tropospheric clouds (mostly below $16 \mathrm{~km}$ ) are not cleared. 


\section{REFERENCES}

[1] Winker, D. M., McGill, M. and Hunt, W. H., "Initial Performance Assessment of CALIOP," Geophys. Res. Lett., 34, L19803, doi: 10.1029/2007GL030135, (2007).

[2] Vaughan, M., Young, S., Winker, D., Powell, K., Omar, A., Liu, Z., Hu, Y., and Hostetler, C., "Fully automated analysis of space-based lidar data: an overview of the CALIPSO retrieval algorithms and data products," Proc. SPIE, 5575, 16-30 (2004).

[3] Bloom, S., da Silva, A., Bosilovich, M., Dee, D., Chern, J.-D., Pawson, S., Schubert, S., Sienkiewicz, M., ,Stajner, I., Tan, W.-W., Wu, M.-L., "Documentation and Validation of the Goddard Earth Observing System (GEOS) Data Assimilation System - Version 4 . Technical Report Series on Global Modeling and Data Assimilation" 104606, 26, (2005).

[4] Hostetler, C. A., Z. Liu, J. Reagan, M. Vaughan, D. Winker, M. Osborn, W. H. Hunt, K. A. Powell, and C. Trepte, "CALIOP Algorithm Theoretical Basis Document - Part 1: Calibration and Level 1 Data Products", PC-SCI-201, NASA Langley Research Center, Hampton, VA, 2006. (available at http://www-calipso.larc.nasa.gov/resources/project_documentation.php )

[5] Pitts, M. C., Thomason, L. W., Poole, L. R., and Winker., D. M., "Characterization of polar stratospheric clouds with space borne lidar: CALIPSO and 2006 Antarctic season," Atmos. Chem. Phys., 7, 5207-5228, 2007 www.atmos-chem-phys.net/7/5207/2007/ (2007).

[6] Carn, S. A., Krotkov, N. A., Yang, K., Hoff, R. M., Prata, A. J., Krueger, A. J., Loughlin, S. C., Levelt, P. F., "Extended observations of volcanic SO2 and sulfate aerosol in the stratosphere," Atmos. Chem. Phys. Discuss., 7, 2857-2871, /www.atmos-chem-phys-discuss.net/7/2857/2007/ (2007).

[7] Thomason, L. W., Pitts, M. C., and Winker, D. M., "CALIPSO observations of stratospheric aerosols: A preliminary assessment," Atmos. Chem. Phys., 7, 5283-5290, www.atmos-chem-phys.net/7/5283/2007/ (2007). 